\title{
Postconditioning improvement effects of ulinastatin on brain injury following cardiopulmonary resuscitation
}

\author{
BO SUI $^{1 *}$, YONGWANG LI $^{1 *}$ and LI MA ${ }^{2}$ \\ Departments of ${ }^{1}$ Anesthesiology and ${ }^{2}$ Gynecology and Obstetrics, \\ The Second Artillery General Hospital, Beijing 100088, P.R. China \\ Received January 23, 2014; Accepted June 5, 2014
}

DOI: $10.3892 /$ etm.2014.1876

\begin{abstract}
The aim of the present study was to determine the effects of ulinastatin (UTI) on brain injury in rats subjected to cardiopulmonary resuscitation (CPR) following asphyxial cardiac arrest (CA) and identify the underlying mechanisms. In total, 100 healthy male Wistar rats were randomly divided into control and treatment groups $(n=50)$. After 4 min of asphyxial CA, all the rats were immediately subjected to CPR. The treatment group animals were administered $15 \mathrm{mg} / \mathrm{kg}$ UTI at the onset of resuscitation. The mortality rate in the two groups was recorded at $24 \mathrm{~h}$ post-resuscitation. In addition, neurological function was evaluated at 24, 48 and $72 \mathrm{~h}$ post-resuscitation using a neurological deficit scale (NDS). Furthermore, the effects of UTI on the Toll-like receptor 4 (TLR4) signaling pathway in brain tissues were determined by assessing TLR4 mRNA expression, nuclear factor (NF) $-\kappa B$ activity and tumor necrosis factor (TNF)- $\alpha$ and interleukin (IL)-6 levels at 1, 3, 6, 12, 24, 48 and $72 \mathrm{~h}$ post-resuscitation. After $24 \mathrm{~h}$, the mortality rate significantly decreased in the treatment group when compared with the control animals (10 vs. $30 \%$; $\mathrm{P}<0.05)$. Additionally, an overt improvement was observed in the NDS score following UTI treatment when compared with the control $(\mathrm{P}<0.01)$. Finally, statistically significant decreases in the levels of TLR4 mRNA expression, NF- $\kappa \mathrm{B}$ activity and TNF- $\alpha$ and IL-6 were observed in the treatment group at each time point $(\mathrm{P}<0.01)$. Therefore, UTI treatment at the onset of CPR significantly inhibits the TLR4 signaling pathway, thereby alleviating the inflammatory responses following resuscitation and improving neurological function.
\end{abstract}

Correspondence to: Dr Yongwang Li,Department of Anesthesiology, The Second Artillery General Hospital, 16th Xinjiekouwai Street, Xicheng, Beijing 100088, P.R. China

E-mail: liyongwangmed@163.com

*Contributed equally

Key words: cardiac arrest, cardiopulmonary resuscitation, ulinastatin, inflammation, Toll-like receptor 4 signaling pathway

\section{Introduction}

Statistical data show that $\sim 1$ million patients with cardiac arrest (CA) are recorded annually in the United States and Europe (1). However, treatment of CA with cardiopulmonary resuscitation (CPR) often leads to an unsatisfactory outcome. For example, $30-40 \%$ of patients that have undergone CPR achieve a return of spontaneous circulation (ROSC), 10-30\% are completely healed and discharged from hospital, while the remaining patients eventually succumb to the illness. In addition, patients that have been successfully resuscitated can often experience permanent neurological complications, including cognitive impairment and motor deficit $(2,3)$. Therefore, providing an effective regimen for the treatment and prevention of neurological injury following CPR is important.

Organ injury following successful CPR from CA is considered to be associated with systemic inflammatory responses; levels of various cytokines and lipopolysaccharide (LPS) have been shown to be markedly elevated in patients that have been successfully resuscitated from CA $(4,5)$. LPS can be identified by the cell-surface Toll-like receptor 4 (TLR4), which induces inflammatory responses and promotes the production of a number of inflammatory cytokines, resulting in a sepsis-like syndrome. The dynamic changes in the levels of inflammatory cytokines and LPS have been shown to be closely associated with prognosis in patients that have undergone CPR (6). A previous study demonstrated that neurological injury following CPR is associated with the activation of cerebral inflammatory responses, with the TLR4 signaling pathway playing a contributory role in the occurrence of neurological injury (7). Under cerebral ischemia and anoxia, the activated TLR4 promotes the expression of nuclear factor (NF)- $\kappa \mathrm{B}$ and induces the production of cytokines, such as tumor necrosis factor (TNF)- $\alpha$ and interleukin (IL)-6, thereby causing inflammation and neurological injury (7). Therefore, it is hypothesized that the TLR4 signaling pathway may be inhibited by hypoxic preconditioning to attenuate inflammatory responses and neurological injury; thus, protecting brain function. Notably, a significantly reduced area of cerebral infarction and an alleviation of inflammatory responses in the brain have been observed in TLR4 knockout mice following cerebral ischemia (8). However, attenuation of brain injury following 
CA by hypoxic preconditioning remains difficult in clinical settings. Therefore, postconditioning with an effective medicine is of vital importance.

Ulinastatin (UTI), a urinary trypsin inhibitor extracted and purified from human urine, has been shown to possess anti-inflammatory properties, suppressing the infiltration of neutrophils and the release of elastinase and chemokines (9). In addition, UTI protects mitochondrial function by reducing the calcium overload in injured cells and exhibits protective effects against ischemia-reperfusion (I/R) injury in the heart, lung, liver and kidney (9). Furthermore, previous studies have demonstrated that UTI can alleviate LPS-induced lung and kidney injury by inhibiting inflammatory responses in these organs $(10,11)$. Thus, we hypothesized that UTI may protect against cerebral I/R injury following CPR and inhibit TLR4-induced inflammatory responses in the brain following resuscitation. In the present study, a rat model of CPR following asphyxial CA was established, in which the effects of UTI on the TLR4 signaling pathway were evaluated, as well as the protective mechanisms against cerebral I/R injury in rats subjected to CPR following CA.

The effects of UTI were investigated with regard to the mortality rate, TLR 4 mRNA expression, NF- $\mathrm{KB}$ activity and the levels of TNF- $\alpha$ and IL-6. The aim of the present study was to determine whether UTI improved neurological function; thus, may be used in combination with CPR for the treatment of brain injury following CA.

\section{Materials and methods}

Animal treatments. The study was approved by the Experimental Animal Protection and Ethics Committee of the Second Artillery General Hospital (Beijing, China). In total, 100 male Wistar rats (age, 2 months; weight, 250-350 g) were randomly assigned to control and treatment groups $(\mathrm{n}=50)$. After $4 \mathrm{~min}$ of asphyxial CA, all the rats were immediately subjected to CPR. The treatment group animals were administered $15 \mathrm{mg} / \mathrm{kg}$ UTI (Techpool Bio-Pharma, Guangdong, China) at the onset of resuscitation (Fig. 1).

Establishment of a rat model of CPR following asphyxial CA. Asphyxial CA was induced as previously described (12-16). Rats in the two groups were anesthetized with $30 \mathrm{mg} / \mathrm{kg}$ chloral hydrate, orally intubated and mechanically ventilated using a small-animal ventilator. The tidal volume, respiratory rate, inspiratory/expiratory ratio (I/E) and the fraction of inspired oxygen were set at $8 \mathrm{ml} / \mathrm{kg}, 40$ breaths $/ \mathrm{min}, 1 / 2$ and 1.0 , respectively. Next, the rats were intravenously injected with $2 \mathrm{mg} / \mathrm{kg}$ vecuronium bromide to prevent spontaneous respiration. The rectal temperature was maintained at $37.5 \pm 0.3^{\circ} \mathrm{C}$ with a heating lamp during the induction of $\mathrm{CA}$. The femoral vein and artery were cannulated in order to provide fluid and medications and to monitor the arterial pressure, heart rate (HR) and arterial blood gas.

Baseline physiological variables were recorded continuously for 10 min following surgery. CA was defined as a reduction in the mean arterial pressure (MAP) to a value of $<10 \mathrm{mmHg}$ after ventilation had been discontinued for $\sim 3 \mathrm{~min}$. After $1 \mathrm{~min}$ of CA, CPR was performed with continuous ventilation and external cardiac compressions at a rate of
$200 / \mathrm{min}$, along with an intravenous injection of $0.01 \mathrm{mg} / \mathrm{kg}$ epinephrine and $1 \mathrm{mmol} / \mathrm{kg}$ sodium bicarbonate. Successful CPR was defined as an achievement of ROSC, indicated by a rise in the MAP to a value of $>50 \mathrm{mmHg}$. CPR was considered to have failed if no sign of ROSC was observed during the 5 min post-resuscitation.

Following resuscitation, the rats were mechanically ventilated with an increased $\mathrm{I} / \mathrm{E}$ ratio of $1 / 1.5$ and treated with a continuous infusion of $8 \mathrm{ml} / \mathrm{h}$ lactated Ringer's solution until the restoration of adequate spontaneous respiration. The rats were then weaned from the ventilator, extubated and observed for $10 \mathrm{~min}$. This was followed by arteriovenous ligation and skin sutures if there were no abnormalities observed in the circulation and respiration. Following restoration in an oxygen tank for $30 \mathrm{~min}$, the rats were finally returned to their respective cages with access to food and water ad libitum.

Determination of the mortality rate. The mortality rate in the two groups was recorded at $24 \mathrm{~h}$ post-resuscitation.

Assessment of the circulatory function. MAP and HR were determined for all the animals during the first $60 \mathrm{~min}$ post-resuscitation. The time to CA (TCA) and time to ROSC (TROSC) were also recorded. The TCA was defined as the time from the initiation of ventilation to the onset of $\mathrm{CA}$, while the TROSC was defined as the time from the start of resuscitation to ROSC.

Sample collection. At 1, 3, 6, 12, 24, 48 and 72 h post-resuscitation, all the rats were decapitated, and their brains quickly removed and placed on ice for dissection. Following washing in ice-cold normal saline, the surface water on the organs was gently blotted off with filter paper. Left hemisphere brain tissues were stored in liquid nitrogen, until required for the analysis of TLR 4 mRNA expression and NF- $\kappa \mathrm{B}, \mathrm{TNF}-\alpha$ and IL-6 protein levels.

Determination of brain water content $(B W C)$. A small sample of brain tissue $(\sim 50 \mathrm{mg})$ from the right hemisphere was extracted at $24 \mathrm{~h}$ post-resuscitation, as described previously. The brain tissues were immediately weighed on an electronic analytical balance, dried at $105^{\circ} \mathrm{C}$ for $24 \mathrm{~h}$ and weighed again. The BWC was calculated as follows: (wet weight - dry weight)/wet weight $\times 100 \%$.

Neurological assessment. Neurological function was evaluated in the rats at 24,48 and $72 \mathrm{~h}$ post-resuscitation using a neurological deficit scale (NDS) scoring system (score range, 0-100; score 0, normal; score 100, brain dead; Table I) $(13,14)$.

Isolation of total RNA and cDNA synthesis. Total RNA was extracted from the brain tissue specimens of rats using a TriPure isolation reagent (Roche Diagnostics, Mannheim, Germany), according to the manufacturer's instructions. Briefly, fresh or frozen tissues ( $100 \mathrm{mg}$ ) were homogenized in $1 \mathrm{ml}$ TriPure reagent and submitted to centrifugation at $21,578 \mathrm{xg}$ for $10 \mathrm{~min}$ at $4^{\circ} \mathrm{C}$. Following the addition of $0.2 \mathrm{ml}$ chloroform to the supernatants, the mixture was 
Table I. Modified NDS scores.

\begin{tabular}{|c|c|c|}
\hline Parameter & Points & Maximum points \\
\hline Arousal & & 19 \\
\hline Alerting (normal/stuporous/comatose) & $10 / 5 / 0$ & \\
\hline Eye opening (open spontaneously/open to pain/absent) & $3 / 1 / 0$ & \\
\hline Spontaneous respiration (normal/abnormal/absent) & $6 / 0 / 0$ & \\
\hline Brainstem function & & 21 \\
\hline Olfaction (present/weak/absent) & $3 / 1 / 0$ & \\
\hline Vision (present/weak/absent) & $3 / 1 / 0$ & \\
\hline Papillary light reflex (present/weak/absent) & $3 / 1 / 0$ & \\
\hline Corneal reflex (present/weak/absent) & $3 / 1 / 0$ & \\
\hline Startle reflex (present/weak/absent) & $3 / 1 / 0$ & \\
\hline Whisker stimulation (present/weak/absent) & $3 / 1 / 0$ & \\
\hline Swallowing (present/weak/absent) & $3 / 1 / 0$ & \\
\hline Motor assessment (each side tested and scored separately) & & 6 \\
\hline Strength (normal/weak movement/no movement) & $3 / 1 / 0$ & \\
\hline Sensory assessment (each side tested and scored separately) & & 6 \\
\hline Pain (brisk withdrawal/weak withdrawal/no movement) & $3 / 1 / 0$ & \\
\hline Motor behavior & & 6 \\
\hline Gait coordination (normal/abnormal/absent) & $3 / 1 / 0$ & \\
\hline Balance during walking (normal/abnormal/absent) & $3 / 1 / 0$ & \\
\hline Behavior & & 12 \\
\hline Righting reflex (normal/abnormal/absent) & $3 / 1 / 0$ & \\
\hline Negative geotaxis (normal/abnormal/absent) & $3 / 1 / 0$ & \\
\hline Visual placing (normal/abnormal/absent) & $3 / 1 / 0$ & \\
\hline Turning alley (normal/abnormal/absent) & $3 / 1 / 0$ & \\
\hline Seizures (no seizure/focal seizure/generalized seizure) & $10 / 5 / 0$ & 10 \\
\hline Feeding (normal/abnormal/absent) & $10 / 5 / 0$ & 10 \\
\hline Grooming (normal/abnormal/absent) & $10 / 5 / 0$ & 10 \\
\hline
\end{tabular}

100, normal; 0, brain dead; NDS, neurological deficit scale.

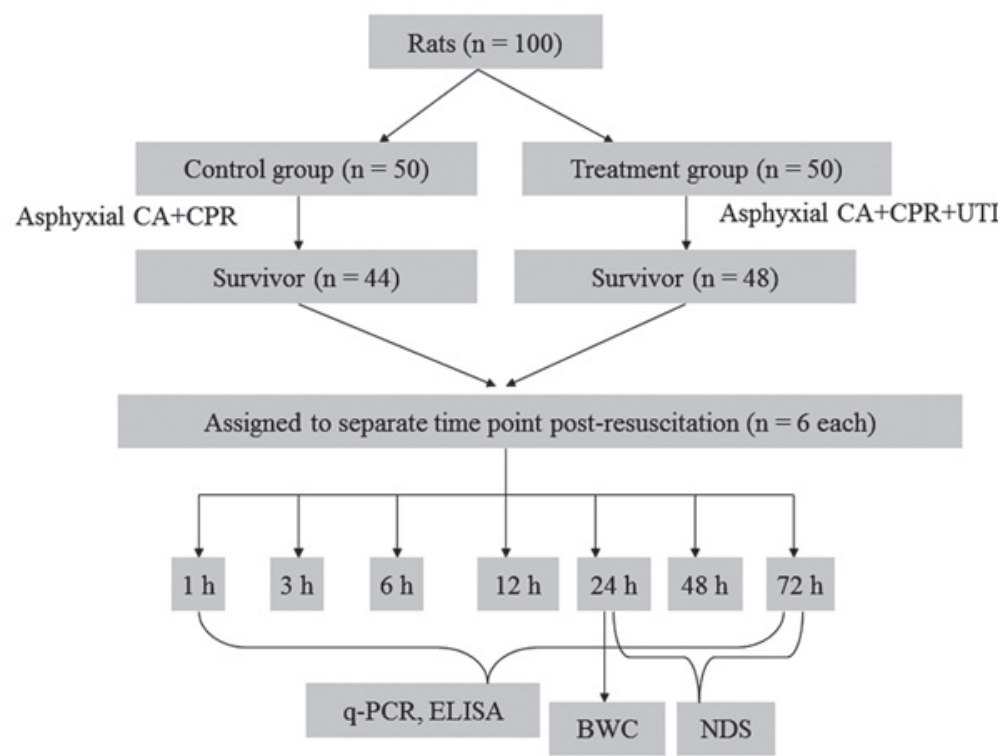

Figure 1. Disposition of rats in the two groups. CA, cardiac arrest; CPR, cardiopulmonary resuscitation; UTI, ulinastatin; qPCR, quantitative polymerase chain reaction; ELISA, enzyme-linked immunosorbent assay; BWC, brain water content; NDS, neurological deficit scale. 
incubated at room temperature for $20 \mathrm{~min}$ with occasional stirring. The samples were then submitted to centrifugation again, as aforementioned. The resulting supernatants were mixed with $0.5 \mathrm{ml}$ isopropanol, incubated for 5-10 min and centrifuged as aforementioned. The pellet containing total RNA was washed with $1 \mathrm{ml}$ ethanol $(75 \%)$ and centrifuged at $8,429 \mathrm{x} \mathrm{g}$ for $5 \mathrm{~min}$ at $4^{\circ} \mathrm{C}$. The RNA pellet was air dried, dissolved in $3 \mathrm{ml}$ diethylpyrocarbonate-treated water and the optical density (OD) values were measured at 260 and $280 \mathrm{~nm}$ on a Lambda $20 \mathrm{UV} / \mathrm{Vis}$ spectrophotometer (Perkin-Elmer, Norwalk, CT, USA). The RNA concentration was calculated as follows: RNA concentration $(\mu \mathrm{g} / \mathrm{ml})=\mathrm{OD}_{260} \mathrm{x}$ dilution factor $\mathrm{x} 40 / 1,000$. RNA purity was assessed by the $\mathrm{OD}_{260} / \mathrm{OD}_{280}$ ratio.

Detection of TLR4 mRNA expression levels. TLR4 gene expression was evaluated using quantitative polymerase chain reaction (qPCR). Plasmids of TLR4 and the housekeeping gene, glyceraldehyde-3-phosphate dehydrogenase (GAPDH), were obtained at 3.67 and $2.67 \times 10^{10}$ copies $/ \mu 1$, respectively, and diluted with sterile water to final concentrations of $1 \times 10^{6}, 1 \times 10^{5}, 1 \times 10^{4}$ and $1 \times 10^{3}$ copies $/ \mu 1$. The qPCR mixture (25 $\mu \mathrm{l}$ ) contained $1 \mathrm{X}$ PCR buffer, $4 \mathrm{mM} \mathrm{MgCl}, 0.4 \mu \mathrm{M}$ each primer, $0.4 \mu \mathrm{M}$ TaqMan probe, 0.5 units AmpErase Uracil N-Glycosylase, 0.5 units AmpliTaq Gold DNA polymerase, $50 \mathrm{ng}$ cDNA, double distilled water, $0.2 \mathrm{mM}$ dUTP and $0.1 \mathrm{mM}$ dATP, dGTP and dCTP.

qPCR was conducted using an ABI Prism 7500 SDS RT-PCR system (Applied Biosystems, Foster City, CA, USA). The reaction conditions for the amplification of TLR 4 and GAPDH were 40 cycles of $50^{\circ} \mathrm{C}$ for $2 \mathrm{~min}, 95^{\circ} \mathrm{C}$ for $2 \mathrm{~min}, 95^{\circ} \mathrm{C}$ for $15 \mathrm{sec}$ and $60^{\circ} \mathrm{C}$ for $60 \mathrm{sec}$. The amplified products for TLR 4 and GAPDH were 122 and 138 bp in size, respectively. The primers and fluorescent probes used for qPCR were as follows: TLR4 forward, 5'-TGAGAAACGAGCTGGTAAAGAATT-3', reverse, 5'-GTGGAAGCCTTCCTGGATGATG-3'; and probe, 5'-AGTGCCCCGCTTTCAGCTTTGCCT-3'; GAPDH forward, 5'-CATGACCTTCCGTGTTCCTACC-3', reverse, 5'-TAGCCCAGGATGCCCTTCAG-3' and probe, 5'-CCTCAGACGCCTGCTTCACCACCT-3'.

The threshold level was set at 10-times the standard deviation (SD) of the baseline fluorescence measured during PCR cycles $3-15$. The threshold cycle $(\mathrm{Ct})$ was defined as the cycle number at which fluorescence passed the fixed threshold, normalized against GAPDH. Standard curves of the Ct values (serial dilutions of the control plasmids plotted against the logarithm of the copy numbers) were constructed for TLR4 and GAPDH. The correlation coefficients of the standard curves for TLR4 and GAPDH were 0.986 and 0.971 , respectively. The absolute copy numbers of TLR 4 mRNA in each unknown sample were then calculated based on the $\mathrm{Ct}$ values. The GAPDH mRNA copy number in each sample was used to normalize TLR4 mRNA expression levels.

Extraction of nucleoproteins from the brain tissues. Nucleoproteins were extracted from the brain tissues using a nucleoprotein extraction kit (Active Motif, Carlsbad, CA, USA). Briefly, $200 \mathrm{mg}$ tissue samples were homogenized in $2 \mathrm{ml}$ nuclear extraction buffer (NEB) A. The homogenates were then centrifuged at $599 \mathrm{x} \mathrm{g}$ for $30 \mathrm{sec}$, and the superna- tants containing the complete nuclei were incubated on ice for $5 \mathrm{~min}$. Following centrifugation at $3,746 \mathrm{x}$ g for $10 \mathrm{~min}$ at $4^{\circ} \mathrm{C}$, the nuclear precipitates (pellet) were resuspended in $150 \mu \mathrm{l}$ NEB B and incubated for $30 \mathrm{~min}$ on ice. A final centrifugation at $29,371 \mathrm{x} \mathrm{g}$ for $1 \mathrm{~min}$ at $4^{\circ} \mathrm{C}$ yielded nucleoproteins in the supernatants, which were stored at $-70^{\circ} \mathrm{C}$ until required for the assessment of protein concentrations using the Coomassie Brilliant Blue G-250 method (8).

Detection of $N F-\kappa B$ activity. $\mathrm{NF}-\kappa \mathrm{B}$ activity levels in the nuclear extracts were detected by a specific high-sensitive enzyme-linked immunosorbent assay (ELISA), using a TransAM NF- $\kappa \mathrm{B}$ detection kit (Active Motif), according to the manufacturer's instructions. Antibodies were used at a 1:1,000 dilution in antibody binding buffer and incubations were performed at room temperature for $1 \mathrm{~h}$. The reactions were visualized using $100 \mu \mathrm{l}$ tetramethylbenzidine (TMB) chromogenic substrate for $10 \mathrm{~min}$ in the dark, and were stopped following the addition of $100 \mu 1$ stop solution. Absorbance was measured immediately at $450 \mathrm{~nm}$ on a microplate reader.

Detection of TNF- $\alpha$ and IL-6 levels. TNF- $\alpha$ and IL-6 levels were assessed using specific ELISA kits (Sigma-Aldrich, St. Louis, MO, USA). Briefly, samples or standards (2,000, $1,000,500,250$ and $125 \mathrm{pg} / \mathrm{ml}$ ) were added to the wells. Following incubation for $1 \mathrm{~h}$ at $37^{\circ} \mathrm{C}$, and four washes in $350 \mu \mathrm{l}$ washing solution, the plates were incubated in the presence of $100 \mu \mathrm{l}$ biotin antibodies for $1 \mathrm{~h}$ at $37^{\circ} \mathrm{C}$. Next, the plates were washed and incubated with $100 \mu 1$ enzyme binding buffer for $30 \mathrm{~min}$ at $37^{\circ} \mathrm{C}$. The reactions were visualized using $100 \mu 1 \mathrm{TMB}$ chromogenic substrate for $15-20 \mathrm{~min}$ in the dark, and stopped following the addition of $100 \mu 1$ stop solution. Absorbance was measured within $15 \mathrm{~min}$ at $450 \mathrm{~nm}$ on a microplate reader. Based on the measured OD values, the protein levels of TNF- $\alpha$ and IL- 6 were determined using the corresponding standard curves.

Statistical analysis. Statistical analyses were performed using SPSS statistical software version 12.0 (SPSS, Inc., Chicago, $\mathrm{IL}$, USA). All the data are expressed as the mean $\pm \mathrm{SD}$. The Student's t-test was used to compare differences between the two groups, where $\mathrm{P}<0.05$ was considered to indicate a statistically significant difference, and $\mathrm{P}<0.01$ indicated a higher degree of statistical significance.

\section{Results}

Baseline characteristics. No statistically significant differences were observed in the baseline characteristics, including the body weight, HR, MAP and NDS, between the two groups (data not shown).

Analysis of the mortality rate, TCA, TROSC and BWC. As shown in Table II, at $24 \mathrm{~h}$ post-resuscitation, six and two mortalities were recorded in the control and treatment groups, respectively; a statistically significant difference was observed in the mortality rates $(\mathrm{P}<0.01)$. TROSC values were significantly higher in the control animals as compared with the treatment group $(99.3 \pm 16.6$ vs. $73.9 \pm 22.4 \mathrm{sec} ; \mathrm{P}<0.01)$. In addition, the BWC was markedly reduced following 
Table II. Comparison of mortality rates, TCA, TROSC, BWC and NDS scores between the control and treatment groups.

\begin{tabular}{lcc}
\hline Variable & Treatment group & Control group \\
\hline Mortality rate, $(\mathrm{n}=50)$ & $2 / 50(4)^{\mathrm{a}}$ & $6 / 50(12)$ \\
TCA, sec $(\mathrm{n}=50)$ & $190.3 \pm 19.6$ & $191.1 \pm 20.8$ \\
TROSC, sec $(\mathrm{n}=42)$ & $73.9 \pm 22.4^{\mathrm{a}}$ & $99.3 \pm 16.6$ \\
BWC $(\mathrm{n}=6)$ & $77.33 \pm 4.5^{\mathrm{a}}$ & $84.06 \pm 1.83$ \\
NDS $(\mathrm{n}=6)$ & & \\
$24 \mathrm{~h}$ & $69.44 \pm 6.3^{\mathrm{a}}$ & $54.38 \pm 6.8$ \\
$48 \mathrm{~h}$ & $73.77 \pm 5.69^{\mathrm{a}, \mathrm{b}}$ & $63.44 \pm 6.48^{\mathrm{b}}$ \\
$72 \mathrm{~h}$ & $88.55 \pm 5.66^{\mathrm{a}, \mathrm{c}}$ & $70.44 \pm 8.62^{\mathrm{c}}$
\end{tabular}

Results are expressed as the mean $\pm \mathrm{SD} . \mathrm{BWC}=$ (wet weight - dry weight)/wet weight $x 100$. ${ }^{\mathrm{P}} \mathrm{P}<0.01$, vs. control group; ${ }^{\mathrm{b}} \mathrm{P}<0.05$, vs. $24 \mathrm{~h}$ post-resuscitation; ${ }^{\circ} \mathrm{P}<0.05$, vs. $48 \mathrm{~h}$ post-resuscitation; TCA, time to cardiac arrest; TROSC, time to return of spontaneous circulation; BWC, brain water content; NDS, neurological deficit score; SD, standard deviation.

treatment with UTI when compared with the control rats $(77.33 \pm 4.55$ vs. $84.06 \pm 1.83 ; \mathrm{P}<0.01)$. However, no statistically significant difference in the TCA was observed between the control and treatment groups (191.1 \pm 20.8 vs. $190.3 \pm 19.6 \mathrm{sec} ; \mathrm{P}>0.05)$.

Evaluation of neurological function using the NDS scores. Neurological data are summarized in Table II. The NDS scores were similar at the baseline in the two groups of rats. At 24, 48 and $72 \mathrm{~h}$ post-resuscitation, the NDS scores were significantly higher in the treatment group when compared with control animals $(\mathrm{P}<0.01)$. In addition, a statistically significant increase was observed in the NDS scores at $48 \mathrm{~h}$ post-resuscitation when compared with the values obtained at $24 \mathrm{~h}$ for each group $(\mathrm{P}<0.05)$; the trend continued to $72 \mathrm{~h}$.

Effect of UTI on TLR4 gene expression levels. According to the qPCR results (Fig. 2), TLR4 mRNA expression was detected in the brain tissues collected from all the animals at $1 \mathrm{~h}$ after resuscitation. Peak expression was observed between 3 and $6 \mathrm{~h}$, prior to markedly decreasing after $12 \mathrm{~h}$, although expression remained detectable at 72 h. Notably, TLR4 gene expression was significantly reduced in the treatment group as compared with the control rats at each time point $(\mathrm{P}<0.05)$.

Evaluation of $N F-\kappa B$ activity levels. As shown in Fig. 3, NF- $\kappa \mathrm{B}$ activity was detected at $1 \mathrm{~h}$ post-resuscitation in the two groups. The values increased and peaked between 3 and $6 \mathrm{~h}$. At $24 \mathrm{~h}, \mathrm{NF}-\kappa \mathrm{B}$ activity was significantly reduced and continued to decrease further, although a degree of activity was detected at $72 \mathrm{~h}$. Notably, a significant reduction in the NF- $\kappa \mathrm{B}$ activity levels was observed in the treatment group at each time point when compared with the control animals $(\mathrm{P}<0.05) . \mathrm{NF}-\kappa \mathrm{B}$ activity levels were consistent with the trends observed for TLR4 mRNA expression.

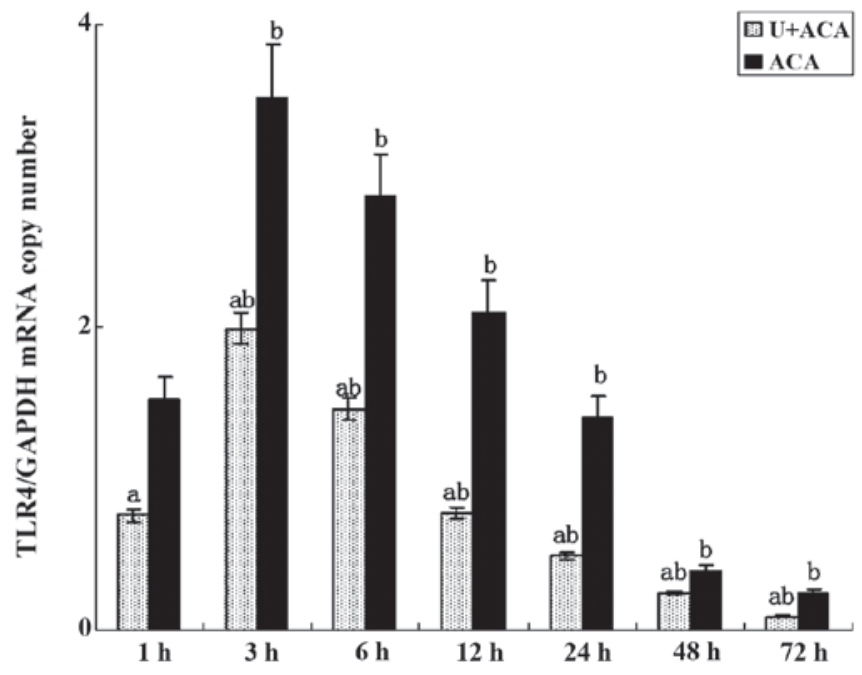

Figure 2. Effect of UTI on TLR4 gene expression in the control and treatment groups $(n=6)$. ${ }^{\mathrm{a}} \mathrm{P}<0.01$, vs. ACA group; ${ }^{\mathrm{b}} \mathrm{P}<0.01$, vs. previous time point. TLR4, Toll-like receptor 4; U or UTI/U, ulinastatin; ACA, asphyxial cardiac arrest.

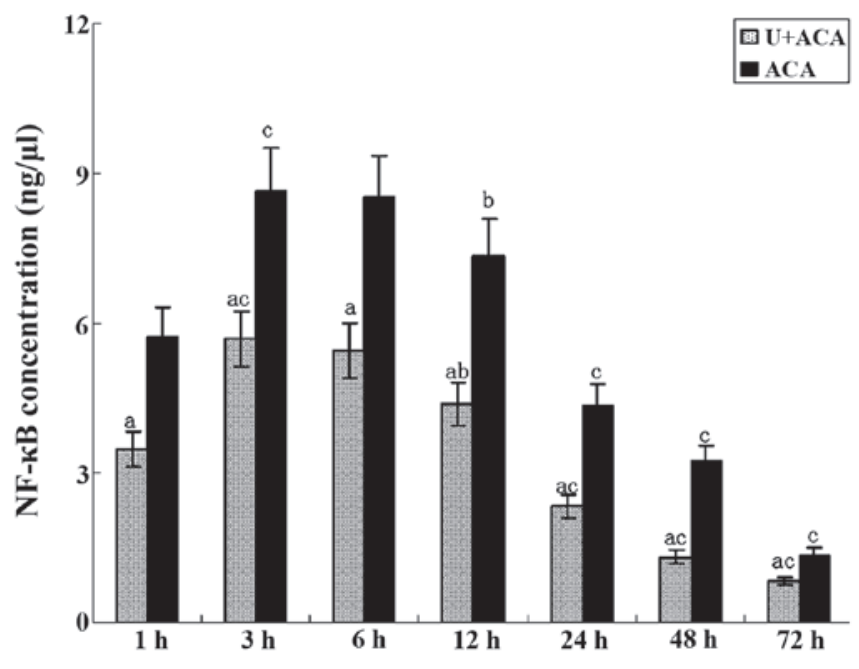

Figure 3. Effect of UTI on NF- $\kappa \mathrm{B}$ activity. ${ }^{\mathrm{a}} \mathrm{P}<0.01$, vs. ACA group; ${ }^{\mathrm{b}} \mathrm{P}<0.05$ and ${ }^{\mathrm{c}} \mathrm{P}<0.01$, vs. previous time point $(\mathrm{n}=6)$. U or UTI, ulinastatin; NF, nuclear factor; ACA, asphyxial cardiac arrest.

Effect of UTI on TNF- $\alpha$ and IL-6 production. As shown in Figs. 4 and 5, the ELISA results revealed changes in the cytokine levels similar to those observed for TLR4 gene expression and NF- $\kappa \mathrm{B}$ activity. TNF- $\alpha$ and IL- 6 were readily secreted in the brain cells at $1 \mathrm{~h}$ post-resuscitation. TNF- $\alpha$ levels peaked at $3 \mathrm{~h}$ and remained high prior to a significant decrease observed at $24 \mathrm{~h}$ (Fig. 4). IL-6 levels reached the highest value at $12 \mathrm{~h}$ and gradually decreased thereafter (Fig. 5). Minimal production of TNF- $\alpha$ and IL- 6 was observed at $72 \mathrm{~h}$ post-resuscitation. Notably, significantly lower levels of TNF- $\alpha$ and IL-6 were observed in the UTI-treated animals at each time point when compared with the control group $(\mathrm{P}<0.05)$.

\section{Discussion}

Patients that are successfully resuscitated from CA often experience neurological complications, including cognitive impairment and motor deficit, which potentially incapacitate 


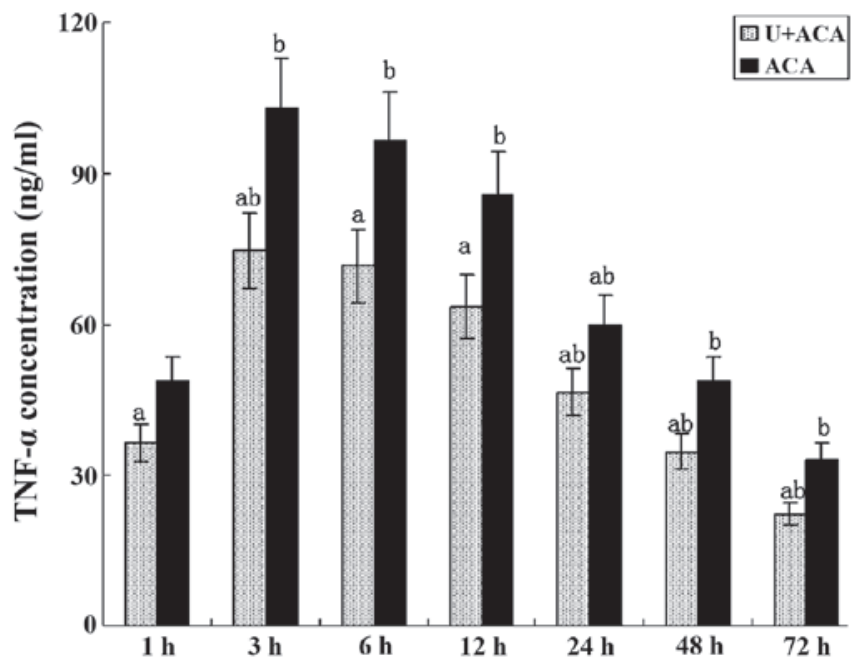

Figure 4. Effect of UTI on TNF- $\alpha$ levels. ${ }^{a} \mathrm{P}<0.01$, vs. ACA group; ${ }^{\mathrm{b}} \mathrm{P}<0.01$, vs. previous time point $(n=6)$. U or UTI, ulinastatin; TNF, tumor necrosis factor; ACA, asphyxial cardiac arrest.

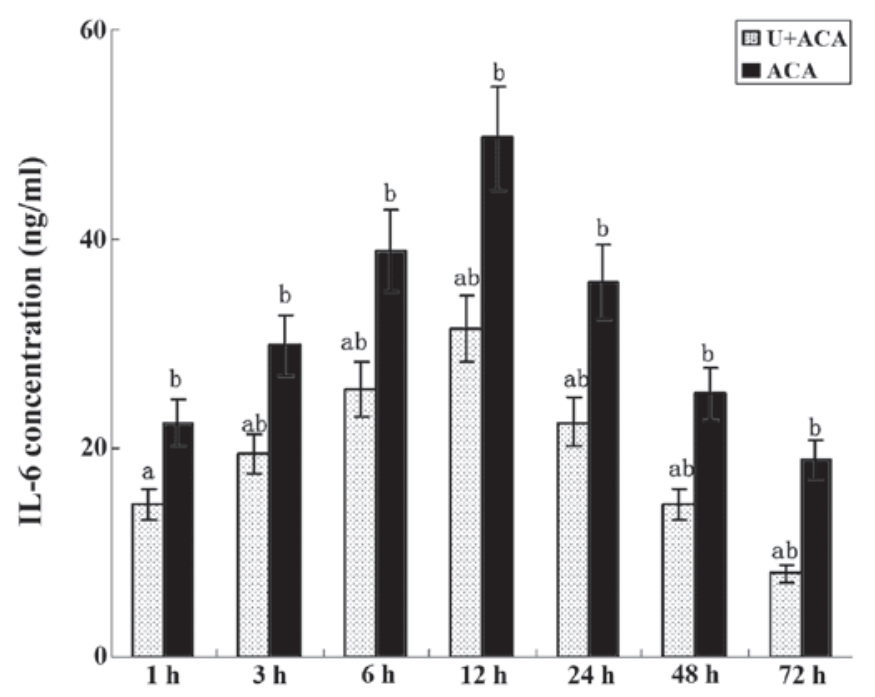

Figure 5. Effect of UTI on IL-6 levels. ${ }^{\mathrm{a}} \mathrm{P}<0.01$, vs. ACA group; ${ }^{\mathrm{b}} \mathrm{P}<0.01$, vs. previous time point $(n=6)$. UTI, ulinastatin; IL, interleukin; ACA, asphyxial cardiac arrest.

the individuals and may result in mortality $(2,3)$. Thus, providing an effective regimen for neurological injury attenuation following CPR is important. The TLR4 inflammatory signaling pathway has previously been reported to play a critical role in brain injury following CPR, since brain injury has been shown to be alleviated by inhibiting the TLR4 signaling pathway via hypoxic preconditioning (7). Therefore, hypoxia-based strategies have been widely used to investigate the mechanisms involved in the pathogenesis of cerebral ischemic injury. However, since the onset of CA is unpredictable, hypoxic preconditioning is not applicable for patients experiencing CA. UTI, a urinary trypsin inhibitor, has been shown to possess anti-inflammatory properties and attenuate LPS-induced acute lung injury (10), inhibit systemic inflammatory responses resulting from pulmonary I/R (11) and alleviate pulmonary I/R injury via the inhibition of TNF- $\alpha$ expression in rats (17). In addition, previous studies have demonstrated that UTI suppresses the elevation of IL-6 and IL-8 levels in patients undergoing coronary artery bypass grafting under extracorporeal circulation (18), alleviates forebrain I/R injury by inhibiting the production of superoxide radicals and intercellular adhesion molecule-1 (19) and improves oleic acid-induced acute lung injury by reducing TNF- $\alpha$ levels and inducing leukocyte activation (20). In addition, UTI has been proposed as a therapeutic option for endotoxin-associated inflammatory disorders, including acute lung and liver injuries (21), due to its anti-inflammatory properties (22-24). However, whether UTI protects against brain injury by inhibiting the inflammatory responses following CA is yet to be elucidated. Therefore, a prospective rat study was conducted to evaluate the role of UTI. Compared with the control group, the mortality rate was significantly reduced following UTI treatment at $24 \mathrm{~h}$ after resuscitation from $\mathrm{CA}$. In addition, the NDS scores were markedly improved in the treatment group when compared with the control animals at 24,48 and $72 \mathrm{~h}$ post-resuscitation.

TLR4 is a pattern recognition receptor that predominantly recognizes endotoxins. A previous study demonstrated that TLR4 can bind to various exogenous ligands, including heat shock proteins, protein fragments from the extracellular matrix, hyaluronan, heparitin sulfate, vascular fibrin monomer-fibrinogen complex and phylaxin and elastase released from immune cells (25). The suppression of exogenous substance release by UTI may contribute to the inhibitory effects on TLR4 expression. However, further studies are required to clarify these possible mechanisms.

Once TLR4 is activated, the interaction of the TLR4 intracellular domains with the adapter protein, MyD88, promotes the expression of IL-1 receptor-associated kinase and TNF receptor-associated factor 6 , which then upregulate $\mathrm{NF}-\kappa \mathrm{B}$. Activated NF- $\kappa \mathrm{B}$ further stimulates the expression of various inflammatory cytokines, including TNF- $\alpha$, IL-1 and IL-6, resulting in inflammation (26). TNF- $\alpha$ and IL-6 are the most important cytokines regulated by NF- $\kappa \mathrm{B}$ and are considered to play a central role in the development of inflammatory diseases. TNF- $\alpha$ levels have been shown to positively correlate with mortality rates, with high levels inducing hypotension, tissue injury and consequently mortality in animals (27). In addition, IL-6 plasma levels have been demonstrated to be closely associated with survival and mortality (28). Based on these observations, the present study was designed to detect the changes in the levels of NF- $\mathrm{KB}, \mathrm{TNF}-\alpha$ and IL- 6 in a rat model of CPR following asphyxial CA. Significant elevations in the levels of TLR4 gene expression and NF- $\mathrm{kB}$ activity were observed, as well as markedly increased levels of TNF- $\alpha$ and IL- 6 in the brains tissues of rats resuscitated from $\mathrm{CA}$ at each time point. These observations indicate that UTI treatment at the onset of CPR significantly suppresses the TLR4/NF- $\mathrm{KB}$ signaling cascade following resuscitation, thereby alleviating the inflammatory responses in the brain. The overt reduction in the mortality rate and the improvement in the NDS scores were likely to have resulted from UTI exerting anti-inflammatory properties in the brain tissues.

In conclusion, UTI was found to alleviate brain injury following CPR by inhibiting the TLR4 signaling pathway and 
reducing the release of inflammatory cytokines; thus, exerting anti-inflammatory effects.

\section{Acknowledgements}

This study was supported by Beijing Municipal Natural Science Foundation (No. 7142169).

\section{References}

1. Cobb LA, Fahrenbruch CE, Olsufka M and Copass MK: Changing incidence of out-of-hospital ventricular fibrillation, 1980-2000 JAMA 288: 3008-3013, 2002.

2. de Vreede-Swagemakers JJ, Gorgels AP, Dubois-Arbouw WI, et al: Out-of-hospital cardiac arrest in the 1990's: a population-based study in the Maastricht area on incidence, characteristics and survival. J Am Coll Cardiol 30: 1500-1505, 1997.

3. Peters $\mathrm{R}$ and Boyde $\mathrm{M}$ : Improving survival after in-hospital cardiac arrest: the Australian experience. Am J Crit Care 16 240-247, 2007.

4. Adrie C, Adib-Conquy M, Laurent I, et al: Successful cardiopulmonary resuscitation after cardiac arrest as a 'sepsis-like' syndrome. Circulation 106: 562-568, 2002.

5. Neumar RW, Nolan JP, Adrie C, et al: Post-cardiac arrest syndrome: epidemiology, pathophysiology, treatment, and prognostication. A consensus statement from the International Liaison Committee on Resuscitation (American Heart Association, Australian and New Zealand Council on Resuscitation, European Resuscitation Council, Heart and Stroke Foundation of Canada, InterAmerican Heart Foundation, Resuscitation Council of Asia, and the Resuscitation Council of Southern Africa); the American Heart Association Emergency Cardiovascular Care Committee; the Council on Cardiovascular Surgery and Anesthesia; the Council on Cardiopulmonary, Perioperative, and Critical Care; the Council on Clinical Cardiology; and the Stroke Council. Circulation 118: 2452-2483, 2008.

6. Lu YC, Yeh WC and Ohashi PS: LPS/TLR4 signal transduction pathway. Cytokine 42: 145-151, 2008.

7. Li YW, Jin HL, Wang BG, et al: Toll-like receptor 4 signal pathway may be involved in cerebral ischemic tolerance induced by hypoxic preconditioning: experiment with rats. Zhonghua Yi Xue Za Zhi 87: 2458-2462, 2007 (In Chinese).

8. Caso JR, Pradillo JM, Hurtado O, et al: Toll-like receptor 4 is involved in brain damage and inflammation after experimental stroke. Circulation 115: 1599-1608, 2007.

9. Xu L, Ren B, Li M, et al: Ulinastatin suppresses systemic inflammatory response following lung ischemia-reperfusion injury in rats. Transplant Proc 40: 1310-1311, 2008.

10. Bae HB, Jeong CW, Li M, et al: Effects of urinary trypsin inhibitor on lipopolysaccharide-induced acute lung injury in rabbits. Inflammation 35: 176-182, 2012.

11. Ueki M, Taie $\mathrm{S}$, Chujo K, et al: Urinary trypsin inhibitor reduces inflammatory response in kidney induced by lipopolysaccharide. J Biosci Bioeng 104: 315-320, 2007.
12. Xiao F, Pardue S, Arnold T, et al: Effect of ifenprodil, a polyamine site NMDA receptor antagonist, on brain edema formation following asphyxial cardiac arrest in rats. Resuscitation 61: 209-219, 2004

13. Geocadin RG, Malhotra AD, Tong S, et al: Effect of acute hypoxic preconditioning on qEEG and functional recovery after cardiac arrest in rats. Brain Res 1064: 146-154, 2005.

14. Geocadin RG, Ghodadra R, Kimura T, et al: A novel quantitative EEG injury measure of global cerebral ischemia. Clin Neurophysiol 111: 1779-1787, 2000.

15. McCaul CL, McNamara PJ, Engelberts D, et al: Epinephrine increases mortality after brief asphyxial cardiac arrest in an in vivo rat model. Anesth Analg 102: 542-548, 2006.

16. Fink EL, Alexander H, Marco CD, et al: Experimental model of pediatric asphyxial cardiopulmonary arrest in rats. Pediatr Crit Care Med 5: 139-144, 2004.

17. Ren B, Wu H, Zhu J, et al: Ulinastatin attenuates lung ischemia-reperfusion injury in rats by inhibiting tumor necrosis factor alpha. Transplant Proc 38: 2777-2779, 2006.

18. Nakanishi K, Takeda S, Sakamoto A and Kitamura A: Effects of ulinastatin treatment on the cardiopulmonary bypass-induced hemodynamic instability and pulmonary dysfunction. Crit Care Med 34: 1351-1357, 2006.

19. Koga Y, Fujita M, Tsuruta R, et al: Urinary trypsin inhibitor suppresses excessive superoxide anion radical generation in blood, oxidative stress, early inflammation, and endothelial injury in forebrain ischemia/reperfusion rats. Neurol Res 32: 925-932, 2010.

20. Ito K, Mizutani A, Kira S, et al: Effect of Ulinastatin, a human urinary trypsin inhibitor, on the oleic acid-induced acute lung injury in rats via the inhibition of activated leukocytes. Injury 36: 387-394, 2005

21. Inoue $\mathrm{K}$ and Takano $\mathrm{H}$ : Urinary trypsin inhibitor as a therapeutic option for endotoxin-related inflammatory disorders. Expert Opin Investig Drugs 19: 513-520, 2010.

22. Tanaka R, Fujita M, Tsuruta R, et al: Urinary trypsin inhibitor suppresses excessive generation of superoxide anion radical, systemic inflammation, oxidative stress, and endothelial injury in endotoxemic rats. Inflamm Res 59: 597-606, 2010.

23. Wang X, Xue Q, Yan F, et al: Ulinastatin as a neuroprotective and anti-inflammatory agent in infant piglets model undergoing surgery on hypothermic low-flow cardiopulmonary bypass. Paediatr Anaesth 23: 209-216, 2013.

24. Xu CE, Zhang MY, Zou CW and Gou L: Evaluation of the pharmacological function of ulinastatin in experimental animals. Molecules 17: 9070-9080, 2012.

25. Karikó K, Weissman D and Welsh FA: Inhibition of Toll-like receptor and cytokine signaling - a unifying theme in ischemic tolerance. J Cereb Blood Flow Metab 24: 1288-1304, 2004.

26. Aderem A and Ulevitch RJ: Toll-like receptors in the induction of the innate immune response. Nature 406: 782-787, 2000.

27. Raeburn CD, Sheppard F, Barsness KA, et al: Cytokines for surgeons. Am J Surg 183: 268-273, 2002.

28. Song $M$ and Kellum JA: Interleukin-6. Crit Care Med 33 (12 Suppl): S463-S465, 2005. 